\title{
Physical and genetical mapping of rDNA sites in Pennisetum (pearl millet)
}

\author{
C. J. LIU $\ddagger$ I. P. KING*†, T. S. PITTAWAY, S. ABBO§, S. M. READER, T. E. MILLER \& \\ M. D. GALE \\ John Innes Centre, Colney Lane, Norwich NR4 7UH and †Department of Cell Biology, IGER, Plas Gogerddan, \\ Aberystwyth SY23 3EB, Wales, U.K.
}

\begin{abstract}
Two pairs of rDNA sites, with significantly different signal strength, were detected on two pairs of chromosomes of Pennisetum glaucum and $P$. violaceum. Both sites were physically located at the distal ends of the short arms of these two chromosome pairs, with the major pair being located on the two shortest chromosomes. Restriction fragment length polymorphism (RFLP) analysis enabled one of the two pairs of rDNA sites, designated Nor-P1, to be mapped on the fifth linkage group in Pennisetum.
\end{abstract}

Keywords: genetic mapping, in situ hybridization, Pennisetum, physical mapping, rDNA.

\section{Introduction}

High-resolution fluorescence in situ hybridization has been widely used for the physical mapping of DNA sequences. Although only a limited number of experiments have reported the detection of singleand low-copy DNA sequences in plant species, this technique has been used successfully to detect alien chromosomes and chromosome segments and to locate repetitive sequences (see Jiang \& Gill, 1994 for a summary). Such studies have not only contributed to our understanding of plant genome organization, but also provided a powerful means for monitoring and characterizing alien chromosome segments introduced from their wild relatives (e.g. King et al., 1993).

In this paper, we report our mapping results of rDNA sites in Pennisetum, which is part of our effort to link the RFLP-based genetic map of pearl millet (Liu et al., 1994) with its seven pairs of chromosomes. To date, only one rDNA site located on the short arms of the shortest chromosome pair has been observed in pearl millet (Pantulu \& KrishnaRao, 1982). In this work, we confirm this observation and also report a second pair of rDNA sites located on a different pair of chromosomes.

\footnotetext{
*Correspondence. E-mail: ian.king@bbsrc.ac.uk

Present addresses: $\Varangle$ CSIRO Tropical Agriculture, 306 Carmody Road, St Lucia, Brisbane 4067, Australia; §Field Crops, Vegetables and Genetics, Faculty of Agriculture, The Hebrew University of Jerusalem, Rehovot 76100, Israel.
}

\section{Materials and methods}

pTa71, which was isolated from wheat and contains the coding sequences for the $18 \mathrm{~S}, 5.8 \mathrm{~S}$ and $26 \mathrm{~S}$ ribosomal genes and spacer sequences (Gerlach \& Bedbrook, 1979), was used as a probe for both in situ hybridization and RFLP analysis. The in situ hybridization was carried out as described by Reader et al. (1994) using two genotypes: $P$. glaucum accession Tift $23 \mathrm{DB}$ and the $\mathrm{F}_{1}$ from the cross of $P$. violaceum accession IPW $2 \times P$. glaucum accession IP 6271 . The RFLP analysis was carried out using the method described by Liu et al. (1994) with the following six restriction enzymes: DraI, EcoRI, EcoRV, HindIII, Bam HI and TaqI. Eight individuals from each of the following three segregating populations, $P$. glaucum accession LGD-1-B- $10 \times P$. glaucum accession ICMP 85410, Tift $23 \mathrm{DB} \times($ IPW $2 \times$ IP6271) $\mathrm{F}_{1}$, and Tift $23 \mathrm{DB} \times(P$. glaucum accession $\mathrm{IP} 12070 \times P$. mollissimum accession $\mathrm{IPW} 250) \mathrm{F}_{1}$, were screened for polymorphism, and 107 three-way $F_{1}$ plants from Tift $23 \mathrm{DB} \times(\mathrm{IPW} 2 \times \mathrm{IP} 6271) \mathrm{F}_{1}$ were used for the mapping experiment. The program MAPMAKER (version 3) (supplied by E. S. Lander, Whitehead Institute for Biomedical Research, Cambridge, MA, U.S.A.) was used for linkage analysis.

\section{Results and discussion}

As shown in Fig. 1, two pairs of rDNA sites were consistently observed in $P$. glaucum and $P$. violaceum 
when the $F_{1}$ seeds of IPW $2 \times$ IP6271 were analysed using the in situ hybridization technique. The intensity of the signal, located at the distal ends of the chromosomes, of one of these pairs was much stronger than that of the other. The intensity and physical position of the signal on each of the chromosomes carrying either the major or minor rDNA sites appeared to be the same even though each of the chromosomes making up the two homologous pairs in question was derived from two different subspecies. This lends further support to the supposition that the rDNA sites may be consistent across different genotypes in pearl millet, despite the considerable karyotypic variation in the species (Chandola \& Jain, 1970). This hypothesis is also supported by the observation that Tift 23DB also carries two pairs of rDNA sites of the same intensities and physical positions as observed in $P$. glaucum and $P$. violaceum (not shown).

Although the chromosomes of pearl millet differ in length and arm ratios, it is very difficult to identify consistently and reliably individual chromosomes using conventional light microscopy (Pantulu \& Krishna-Rao, 1982). However, in the work reported here we have shown that both pairs of rDNA sites are located at the distal ends of the short arms of two pairs of chromosomes. The observation that the major rDNA site is located on the short arm of the smallest chromosome is in accordance with the previous observation of Pantulu \& Krishna-Rao (1982). The second pair of rDNA sites, which has not previously been reported, appears to be located on the second shortest pair of chromosomes, which have a slightly larger short-to-long arm ratio (Fig. 1).

The genome of pearl millet is highly polymorphic, as revealed by RFLP analysis (Liu et al., 1994). However, this seems not to be the case for the rDNA sites. Of all the genotype-enzyme combinations used in this study, only one revealed polymorphism. This was revealed among the EcoRI digests of the progeny from the cross of Tift $23 \mathrm{DB} \times$ (IP$\mathrm{W} 2 \times \mathrm{IP} 6271) \mathrm{F}_{1}$ : Some six bands were detected and only one segregated. Thus, it was not possible to ascertain whether this was derived from the major or minor pair of rDNA sites, although the former is the more likely candidate because of its much higher copy numbers. Segregation of this single rDNA fragment in the progeny of Tift $23 \mathrm{DB} \times(\mathrm{IP}-$ $\mathrm{W} 2 \times \mathrm{IP} 6271) \mathrm{F}_{1}$ was tested against segregation of the 50 RFLP loci mapped in this population (Liu et al., 1996). The analysis showed that this rDNA locus, designated Nor-Pl, was distally located on linkage group 5 (Fig. 2). Only one locus, Xpsm215.1, was distally located to Xpsm815 in the millet map (Liu et

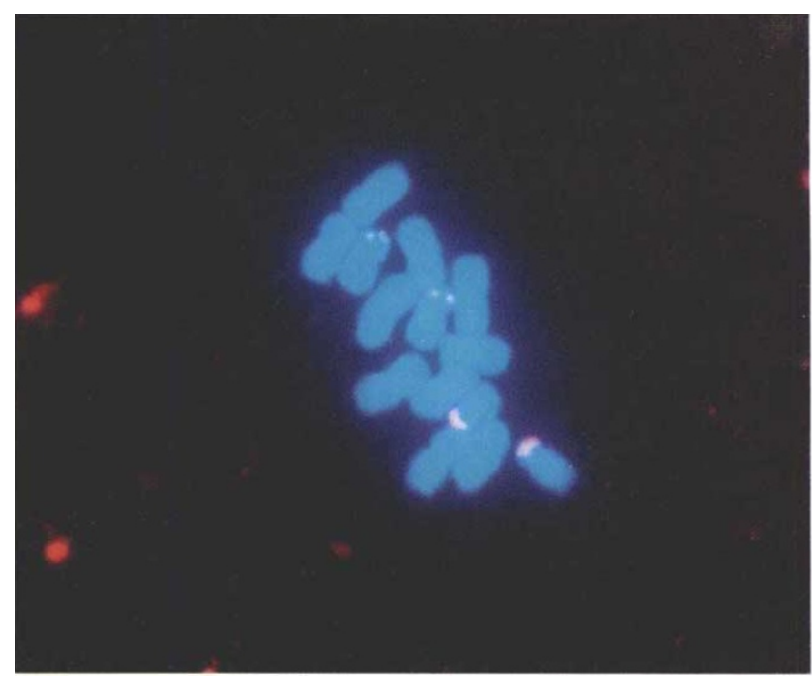

Fig. 1 Mitotic metaphase chromosomes from a root tip of the hybrid between Pennisetum violaceum accession IPW2 and $P$. glaucum accession IP6271 after in situ hybridization with pTa71, showing the two pairs of rDNA sites.

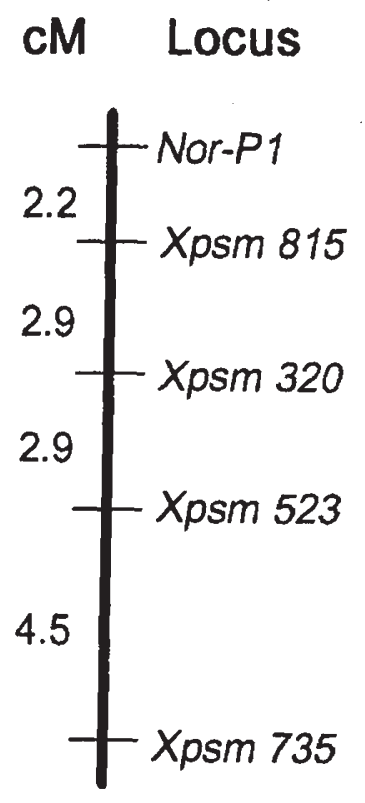

Fig. 2 A linkage map of linkage group 5 of pearl millet, showing the location of the Nor-Pl locus.

al., 1994). Unfortunately, this locus did not segregate in the Tift $23 \mathrm{DB} \times(\mathrm{IPW} 2 \times \mathrm{IP} 6271)$ progeny, and thus its location relative to that of Nor-PI could not be established.

\section{Acknowledgements}

This work was partially funded by the Plant Sciences Research Programme of the Overseas Development

(c) The Genetical Society of Great Britain, Heredity, 78, 529-531. 
Administration, U.K. Thanks to Dr M. H. Mengesha at ICRISAT, Hyderabad, India, and Drs P. OziasAkins and W. W. Hanna at Tifton, GA, U.S.A., for providing the parental genetic stocks. S. Abbo acknowledges fellowship support from the British Council and Ciba Geigy Seeds.

\section{References}

CHANDOLA, R. P AND JAIN, S. N. 1970. Karyomorphological studies in Pennisetum typhoides L. Cytologia, 35, $181-196$.

GERLACH, W. L. AND BEDBROOK, J. R. 1979. Cloning and characterization of ribosomal RNA genes from wheat and barley. Nucl. Acids Res., 7, 1869-1885.

JJANG, J. AND GlLL, B. S. 1994. Nonisotopic in situ hybridization and plant genome mapping: the first 10 years. Genome, 37, 717-725.
KING, I. P., PURDIE, K. A., ORFORD, S. E., READER, S. M. AND MILLER, T. E. 1993. Detection of homoeologous chiasma formation in Triticum durum $\times$ Thinopyrum bessarabicum hybrids using genomic in situ hybridization. Heredity, 71, 369-372.

LIU, C. J., WITCOMBE, J. R., PITTAWAY, T. S., NASH, M., HASH, C. T., BusSO, C. S. AND GAlE, M. D. 1994. An RFLPbased genetic map of pearl millet (Pennisetum glaucum). Theor. Appl. Genet., 89, 481-487.

LIU, C. J., DEVOS, K. M., WITCOMBE, J. R., PITTAWAY, T. S. AND GALE, M. D. 1996. The effect of genome and sex on recombination rates in Pennisetum species. Theor. Appl. Genet., 93, 902-908.

PANTUlu, J. V. AND KRISHNA-RAO, M. 1982. Cytogenetics of pearl millet. Theor. Appl. Genet., 61, 1-17.

READER, S. M., ABBO, S., PURDIE, K. A., KING, 1. P. AND MLLLER, T. E. 1994. Direct labelling of plant chromosomes by rapid in situ hybridization. Trends Genet., 10, $265-266$. 